Debate

Series editors: Susan Lightman \& Peter McCluskey

CONTROVERSIES IN OPHTHALMOLOGY

\title{
The surgical correction of moderate hypermetropia: the management controversy
}

\author{
C N McGhee, S Ormonde, T Kohnen, M Lawless, A Brahma, \\ I Comaish
}

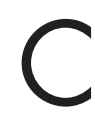
onsiderable debate still surrounds the best management of hypermetropia and to explore the options in this communication a hypothetical patient is considered at two different ages with identical refraction. Four experienced ophthalmic surgeons (CMcG, TK, ML, and $\mathrm{AB})$ who have undertaken cornea and refractive surgery fellowships and have a combined experience of more than 10000 refractive surgical procedures were asked to consider the best options for this hypothetical subject, aided by contributions from two fellows ( $\mathrm{SO}, \mathrm{IC}$ ).

The hypothetical patient is a 25 year old woman with moderate hypermetropia and astigmatism: right eye $+3.00 \mathrm{D} /+1.25 \mathrm{D} \times 85$ and left eye $+5.00 /+1.00 \times 90$. She is currently corrected by spectacles and increasingly intolerant of her rigid gas permeable (RGP) contact lenses, which she has not worn for 6 months. She is keen to seek a solution to her refractive error and self refers for assessment. Members of our expert panel were asked to consider and discuss appropriate options for the patient at age 25 , and also for the same individual with an identical refractive error at age 45 years. For the older age, members of the panel were asked to consider complaints of increasing presbyopia in reaching a management plan.

\section{INTRODUCTION}

The treatment of myopia and myopic astigmatism has evolved significantly since the introduction of radial keratotomy (RK) in the 1970s and the exponential development of photoablative techniques using the $193 \mathrm{~nm}$ excimer laser: photorefractive keratectomy (PRK) and laser in situ keratomileusis (LASIK). ${ }^{1}$ In contrast, the refractive surgical correction of hypermetropia has lagged far behind the advances that have been achieved in treating myopia. ${ }^{1-3}$ To a far greater degree than encountered in myopia, refractive regression and unpredictability have been reported. ${ }^{2}$ In general, the hypermetropic eye, compared to the myopic eye, shows important anatomical variations that have to be considered before surgical treatment. These variations from the normal emmetropic eye include a short axial length, a small anterior segment (narrow anterior chamber angle and smaller corneal diameter), and a higher incidence of angle closure glaucoma, especially in elderly patients because of the progressive enlargement of the human crystalline lens. ${ }^{3}$ The treatment of hypermetropia therefore remains a challenge for the refractive surgeon. Indeed, the successful and permanent treatment of moderate to high hypermetropia is regarded by many as one of the last great frontiers of refractive surgery, and the plethora of early thermal, incisional, laser, and lenticular techniques testified to the lack of a single successful surgical approach. $^{4-23}$

While in childhood and early adulthood many hypermetropic individuals, unlike their myopic cousins, can manage very successfully without a refractive correction, significant hypermetropia is actually more common than clinicians generally perceive. In Britain, perhaps the most informative statistics from a large population are those of Harman (1936), ${ }^{4}$ who studied 30000 subjects older than 16 years of age, and noted the distribution of refractive errors to be myopia $27 \%$, hypermetropia 56\%, and mixed astigmatism $2.25 \%$. In the United States, a more recent study $(1994)^{5}$ highlighted a remarkably similar distribution of refractive error in a study population of 4533, revealing approximately a 2:1 ratio of hypermetropia compared to myopia $(49.0 \% \mathrm{v}$ $26.2 \%)$. In this context, it is an apparent paradox that although hypermetropia is almost twice as common as myopia in many Western populations, ${ }^{6}$ the surgical treatment of hypermetropia has never enjoyed the widespread popularity and acceptance among patients or practitioners that RK, PRK, and LASIK for myopia have achieved. Indeed, in relation to surgical treatment of refractive error it appears to be relatively easier to treat myopia by surgically "flattening" the cornea rather than treat hypermetropia by steepening the axial cornea. ${ }^{\text {? }}$

Many authorities cite the experiments of Lans in 1898 as the first faltering step on the route to surgical correction of hypermetropia. Lans produced increased corneal power by utilising superficial radial burns in rabbit corneas and thereby performed the first thermokeratoplasty (TKP). ${ }^{8}$ Following the widespread success of radial keratotomy in the treatment of myopia, a variety of incisional methods have also been suggested to correct hypermetropia. Yamashita et al (1986) ${ }^{9}$ developed a six-sided incisional technique, subsequently termed hexagonal keratotomy (hex), as a potential method of correcting radial keratotomy overcorrections. Subsequently others modified this procedure to tackle naturally occurring hypermetropia. Unfortunately, despite promise in cadaver models, ${ }^{10}{ }^{11}$ because of unpredictable induced astigmatism, loss of best spectacle corrected visual acuity (BSCVA), and the problems common to incisional surgery, ${ }^{12}{ }^{13}$ vociferous opposition to the technique emerged in the United States in the early to mid 1990s..$^{14-16}$

Fyodorov revived radial thermokeratoplasty as a treatment of hypermetropia in the early 1980s, ${ }^{17}$ utilising the application of a series of 


\section{Debate}

superficial peripheral corneal burns in a pattern similar to radial keratotomy. However, in direct contrast with the biomechanical effects of radial keratotomy, these superficial burns flattened the corneal periphery and steepened the central cornea. Although Fyodorov's group achieved a mean reduction in hypermetropia of $-3.84 \mathrm{D}$, ${ }^{18}$ owing to instability of refraction, marked regression, and overall unpredictability, radial thermokeratoplasty has not been widely adopted to treat hypermetropia. ${ }^{19-21}$ Hypermetropic correction by lamellar techniques such as keratophakia and keratomileusis, or with donor lenticules as in epikeratophakia, have enjoyed limited success because of procedural difficulty, poor predictability, and complications. ${ }^{723}$

Hypermetropic automated lamellar keratoplasty (H-ALK), a precursor of hypermetropic LASIK, used an automated microkeratome to make a deep lamellar dissection that allowed the thin posterior lamellae to bow forwards as a result of normal intraocular pressure. Theoretically, the diameter and depth of the dissection determine the amount of refractive correction achieved. Ruiz developed a nomogram calling for depths of between $54 \%$ and $74 \%$ of the thinnest pachymetry measurement to correct up to 5.0 dioptres of hypermetropia. Potential problems with this technique are low predictability, the risk of progressive myopic shift (or uncontrolled ectasia), and irregular astigmatism. ${ }^{24}{ }^{25}$ This technique was not suggested by any of our authors.

Surgical techniques can be divided into those that correct low hypermetropia (less than +2.50 to +3.00 ) and higher levels of hypermetropia, or into intraocular versus extraocular procedures. Extraocular procedures include laser thermal keratoplasty (LTK), intracorneal segments (Intacs), photorefractive keratectomy (PRK), and laser in situ keratomileusis (LASIK). Intraocular procedures include anterior chamber phakic intraocular lenses (angle supported or iris claw), posterior chamber phakic intraocular lens (IOL) (deformable intraocular refractive corrective lens or intraocular contact lens (ICL)) and phacorefractive surgery (clear lens extraction with either a posterior chamber monofocal IOL or multifocal IOL implantation). ${ }^{23} 26-28$

\section{PREFERRED MANAGEMENT OPTIONS}

All four experts asked for extensive additional information including, among others, a cycloplegic refraction (if the refractive error was not based on a cycloplegic refraction), computed corneal topography, corneal thickness, and reasons for contact lens intolerance. The additional information requested by the panel as the minimum required for appropriate consideration of the subject in relation to possible refractive surgery is highlighted in Table 1. The preferred management options, as stated by each of the experts, are highlighted in Table 2 .

Only three extraocular surgical procedures were suggested to be currently useful by the review panel: laser thermal keratoplasty, surface based photorefractive keratectomy, and LASIK. Three optional management strategies were also felt appropriate to be considered for the hypothetical patient: no treatment and/or refitting of
Table 1 Additional information required before consideration for refractive surgery

Cycloplegic refractions particularly in younger age group

Reason for contact lens intolerance, particularly dry eye symptoms

Has a trial of soft contact lens wear been attempted? History of amblyopia

Ultrasonic measurement of central corneal thickness to determine ablation limit

Computerised videokeratography to exclude corneal warpage or keratoconus

Widefield Orbscan pachymetry to assess areas of focal thinning

Posterior corneal elevation using Orbscan to asses steepness and eccentricity

Central corneal power

Anterior chamber depth from endothelium

Photopic and particularly scotopic pupil size

contact lenses, phakic intraocular lens, and pseudophakic intraocular lens. The key features of each of these procedures, including the expert panel's comments, are highlighted below.

\section{Laser thermal keratoplasty}

The holmium:YAG laser is a solid state laser that uses an infrared wavelength of $2.13 \mu \mathrm{m}$, a pulse length of 200-300 $\mu$ s, and variable pulse repetition rate. It can be used to induce paracentral corneal stromal coagulation in a similar but more controlled manner than TKP, with more moderate and uniform distribution of temperature deep within the stroma. By applying a train of 5-25 pulses to each location the underlying cornea is theoretically heated in a controlled manner to $60^{\circ} \mathrm{C}$, producing focal corneal shrinkage while avoiding the tissue necrosis associated with radial thermokeratoplasty. ${ }^{29}$ Average corneal penetration depth is $480-530 \mu \mathrm{m}$, which is approximately $80-90 \%$ of paracentral corneal thickness and therefore avoids damaging the endothelium. In the early 1990s Seiler and co-workers published results of their pioneering work in this field. ${ }^{26} 3031$ They noted that the induced refractive change was inversely related to distance of treatment application from the centre of the cornea and directly related to laser pulse energy. There are two types of procedure-a contact mode that sequentially delivers laser energy pulses to individual premarked corneal spots with a hand held fibre optic probe, and a non-contact mode that simultaneously delivers laser energy pulses in a symmetric octagonal pattern using a slit lamp delivery system. It has been shown that a precision in application, to within $0.1 \mathrm{~mm}$ of the intended diameter, is necessary for successful and predictable hypermetropic LTK treatment. Therefore, non-contact methods, ${ }^{32}{ }^{33}$ rather than direct application, should achieve greater likelihood of success. Comparisons of using one, two, or three concentric octagonal rings of burns with a non-contact Ho:YAG laser, and the alignment of the burns, have shown that using more than one ring produces a greater refractive change and that applying the concentric rings with the burns radially aligned produces a larger more stable refractive change, preserves physiological asphericity, and provides faster functional recovery. ${ }^{27}{ }^{34}$ 
Tutton and Cherry ${ }^{35}$ reported a mean reduction in hypermetropia of $-2.17 \mathrm{D}$ at 2 years; however, only $25 \%$ of eyes were within plus or minus $1.00 \mathrm{D}$ of intended correction, and $23 \%$ of eyes required retreatment for induced astigmatism. Nano and Muzzin $^{36}$ reported a larger series of 182 eyes ranging between +0.75 and +4.75 preoperatively, where $46 \%$ were within plus or minus $1.00 \mathrm{D}$ of emmetropia at 12 months, with a mean correction of 1.25D. Unfortunately, significant regression of induced refractive change is noted with LTK and this continues to be a significant limitation of this technique with regression up to 2 years post-treatment. ${ }^{79}$ 35-38 Treatment of astigmatism has not been successful and selecting patients with a maximum preoperative astigmatism of less than 1.0 dioptre optimises the outcome. Favourable aspects of the procedure are that it has been shown to be safe and it is well tolerated by patients (as it is minimally invasive and rapid with laser energy applied to the cornea for only a few seconds). Rehabilitation is quick with minimal discomfort. The instruments, consumables, and personnel required are less costly than that which is required for other instruments used to correct refractive error, and Ho:YAG systems are easy to maintain and easily housed in the ophthalmologist's office.

Current recommendations are that LTK be limited to patients older than 40 years and hypermetropia up to +3.0 dioptres. ${ }^{36}{ }^{39}$ On this basis none of our four experts would seriously consider this treatment for our two hypothetical case scenarios, though theoretically it might be used to limited effect in the right, less hypermetropic eye, of the 45 year old subject.

\section{Surface based excimer laser PRK/PARK}

Following the initial clinical promise of excimer laser PRK for myopia and myopic astigmatism, developing excimer laser algorithms for hypermetropia was a logical progression. The principle of hypermetropic PRK (H-PRK) correction is to steepen the anterior corneal curvature and the theoretical recontouring of the cornea for hypermetropic PRK was first described by L'Esperance et al in $1989 .{ }^{40}$ The cornea is sculpted into a steeper convex lens by creating a furrow-like ring zone in the corneal periphery. For the creation of such an annulus of tissue removal, a larger ablation zone than in myopic PRK is necessary. ${ }^{2}$

The earliest clinical studies of human hypermetropic PRK were presented by Dausch and colleagues, ${ }^{41}$ and Anschütz and Ditzen. ${ }^{7}$ Dausch and colleagues treating hypermetropic eyes of up to $+7.50 \mathrm{D}$ noted that $80 \%$ were within plus or minus 1.00D of the intended correction and $80 \%$ had 6/12 unaided visual acuity or better at 1 year. However, all eyes exhibited a transient ring of corneal haze and suffered reduced visual acuity under glare conditions, both conditions being more common in greater attempted corrections, and significant regression was seen at all time points. Anschütz and Ditzen reported 81 hypermetropic patients with 1 year follow up. In a group consisting of 49 eyes with preoperative refractions up to $+5.75 \mathrm{D}, 66 \%$ of eyes were within plus or minus $1.00 \mathrm{D}$ of the intended correction with a mean regression of $+1.00 \mathrm{D}$, post hypermetropic PRK. In an additional 2 year study by Anschütz, ${ }^{7}$ continued regression of induced refractive effect was noted in the second year. Accurate centration of the treatment zone was noted to be more critical than in myopic PRK, if loss of BSCVA was to be avoided.

Clinical outcomes have improved largely because of enlargement of the optical and peripheral zones. A series by Jackson et al ${ }^{42}$ of 25 eyes with hypermetropia up to $+4.0 \mathrm{D}$, and a series of 52 eyes with hypermetropia to a maximum of $+6.0 \mathrm{D}$ by Williams et $a l^{43}$ showed that using an optic zone diameter of $5 \mathrm{~mm}$ with a transition zone diameter of $9 \mathrm{~mm}$ produces more accurate results with reduced hypermetropic regression. In the former series, $80 \%$ of patients achieved within $0.5 \mathrm{D}$ of intended correction and in Williams's series $79 \%$ of patients achieved within $0.5 \mathrm{D}$ of intended correction with stability achieved by 3 months postoperatively. The larger optical zone is less likely to produce adverse visual symptoms or loss of BSCVA in the event of slight decentration, and a larger diameter transition zone theoretically minimises epithelial and stromal regeneration with resultant regression. Conversely however, Dausch et al, ${ }^{44}$ using a $6 \mathrm{~mm}$ optic zone with a $9 \mathrm{~mm}$ transition zone in 68 eyes with

\section{Debate}

Table 2 Preferred management options

\begin{tabular}{|c|c|c|c|c|c|c|c|c|c|c|c|c|c|c|c|c|}
\hline \multirow{4}{*}{$\begin{array}{l}\text { Surgical options } \\
\text { Corneal-extraocular }\end{array}$} & \multicolumn{8}{|c|}{25 year old hypermetrope } & \multicolumn{8}{|c|}{45 year old hypermetrope } \\
\hline & \multirow{2}{*}{\multicolumn{2}{|c|}{$\frac{A}{(M L)}$}} & \multirow{2}{*}{\multicolumn{2}{|c|}{$\frac{\text { B }}{\text { (TK) }}$}} & \multirow{2}{*}{\multicolumn{2}{|c|}{$\frac{C}{(A B)}$}} & \multirow{2}{*}{\multicolumn{2}{|c|}{$\frac{D}{(C M)}$}} & \multirow{2}{*}{\multicolumn{2}{|c|}{$\frac{A}{(M L)}$}} & \multirow{2}{*}{\multicolumn{2}{|c|}{$\begin{array}{l}\text { B } \\
\text { (TK) }\end{array}$}} & \multirow{2}{*}{\multicolumn{2}{|c|}{$\frac{C}{(A B)}$}} & \multirow{2}{*}{\multicolumn{2}{|c|}{$\frac{D}{(C M)}$}} \\
\hline & & & & & & & & & & & & & & & & \\
\hline & $\mathrm{R}$ & $\mathrm{L}$ & $\mathrm{R}$ & $\mathrm{L}$ & $\mathrm{R}$ & $\mathrm{L}$ & $\mathrm{R}$ & $\mathrm{L}$ & R & $\mathrm{L}$ & $\mathrm{R}$ & $\mathrm{L}$ & $\mathrm{R}$ & $\mathrm{L}$ & $\mathrm{R}$ & $\mathrm{L}$ \\
\hline Laser thermal keratoplasty (LTK) & $\mathrm{N}$ & $\mathrm{N}$ & $\mathrm{N}$ & $\mathrm{N}$ & $\mathrm{N}$ & $\mathrm{N}$ & $\mathrm{N}$ & $N$ & $P$ & $N$ & $\mathrm{~N}$ & $\mathrm{~N}$ & $N$ & $N$ & $\mathrm{~N}$ & N \\
\hline Photorefractive keratectomy (PRK) & $\mathrm{N}$ & $\mathrm{N}$ & $\mathrm{N}$ & $N$ & $N$ & $N$ & $N$ & $\mathrm{~N}$ & $\mathrm{~N}$ & $N$ & $\mathrm{~N}$ & $\mathrm{~N}$ & $\mathrm{~N}$ & $N$ & $\mathrm{~N}$ & $\mathrm{~N}$ \\
\hline Laser in situ keratomileusis (LASIK) & $P$ & $\mathrm{~N}$ & Y & Y & $P$ & $P$ & Y & $P$ & $P$ & $\mathrm{~N}$ & Y & $P$ & $P$ & $P$ & $P$ & $P$ \\
\hline \multicolumn{17}{|l|}{ Intraocular refractive surgery } \\
\hline \multicolumn{17}{|l|}{ Phakic intraocular lens } \\
\hline Anterior chamber IOL (angle or claw) & $P$ & $P$ & $\mathrm{~N}$ & $N$ & $N$ & $\mathrm{~N}$ & $\mathrm{~N}$ & $N$ & $P$ & $P$ & $P$ & $P$ & $P$ & $P$ & $N$ & $\mathrm{~N}$ \\
\hline Posterior chamber IOL (ICL) & $P$ & $P$ & $P$ & $P$ & $\mathrm{~N}$ & $\mathrm{~N}$ & $N$ & $N$ & $P$ & $P$ & $P$ & $P$ & $P$ & $P$ & $P$ & $P$ \\
\hline \multicolumn{17}{|l|}{ Crystalline lens surgery } \\
\hline Clear lens extraction/monofocal IOL & $N$ & $\mathrm{~N}$ & $\mathrm{~N}$ & $\mathrm{~N}$ & $N$ & $\mathrm{~N}$ & $\mathrm{~N}$ & $\mathrm{~N}$ & Y & Y & $P$ & $P$ & Y & Y & Y & Y \\
\hline Clear lens extraction/multifocal IOL & $\mathrm{N}$ & $\mathrm{N}$ & $\mathrm{N}$ & $N$ & $\mathrm{~N}$ & $N$ & $N$ & $N$ & $P$ & $P$ & $\mathrm{~N}$ & $\mathrm{~N}$ & $\mathrm{P}$ & $P$ & $\mathrm{~N}$ & $\mathrm{~N}$ \\
\hline Clear lens extraction/piggyback IOL & $N$ & $\mathrm{~N}$ & $\mathrm{~N}$ & $\mathrm{~N}$ & $\mathrm{~N}$ & $\mathrm{~N}$ & $N$ & $\mathrm{~N}$ & $P$ & $P$ & $\mathrm{~N}$ & $\mathrm{~N}$ & $N$ & $\mathrm{~N}$ & $\mathrm{~N}$ & $N$ \\
\hline No surgery, await further developments & Y & Y & Y & Y & Y & Y & Y & Y & & & & & & & & \\
\hline
\end{tabular}

A-D are the 4 members of our expert panel.

$N=$ no, $P=$ possibly,$Y=$ yes. 


\section{Debate}

attempted correction of $+2.0 \mathrm{D}$ to $+8.25 \mathrm{D}$, showed 1.08D of regression over 1 year and Carones et al, ${ }^{45}$ using an ablatable mask in 38 patients for corrections between +1.0D and $+4.0 \mathrm{D}$, showed that a large overcorrection was required to compensate for regression which took a full year to stabilise.

It has also been noted that a significant cylinder may be induced (steep vertically) possibly due to weakening from mid-peripheral tissue removal leading to lid induced "with the rule" astigmatism. ${ }^{45}$

Little has been published on hypermetropic photoastigmatic refractive keratectomy (PARK). Early attempts to treat astigmatism and hypermetropia using an ablatable mask ${ }^{46}$ proved to be unpredictable, largely because of difficulties in centration of the hand held mask system. To obtain the intended correction, it is necessary to perform an oval furrow-like ring zone in the steep meridian. Techniques for astigmatism in combination with low to moderate hypermetropia (up to $+6.50 \mathrm{D}$ ) initially showed promise ${ }^{77}$; however contemporary data suggest an upper limit of $+2.0 \mathrm{D}$ to $+3.5 \mathrm{D}$ spherical equivalent. ${ }^{248}$ Daya et $a l^{49}$ reported a series of 20 patients undergoing hypermetropic PARK. A reduction in cylinder from a mean of $-1.51 \mathrm{D}$ to a mean of -0.44 was achieved, with $92 \%$ of the desired correction achieved at 6 months. Greater predictability was seen with lower levels of astigmatism.

Subepithelial corneal haze remains a universal occurrence, but owing to the ablation profile this is not in the visual axis and it tends to decrease over time..$^{42-44} 4950$ However, halos and glare are frequently reported by subjects, but fortunately these also tend decrease or resolve over time. Healing of H-PRK can result in surface irregularity with surface regularity index and surface asymmetry index significantly greater at 2 years than preoperatively. ${ }^{50}$ All complications pertaining to excimer laser PRK for myopia, in terms of debridement, laser ablation, potential delayed healing, and pharmacological issues also apply to excimer laser treatment for hypermetropia."

Loss of BSCVA is always a concern with any refractive surgery technique. While Williams ${ }^{43}$ reported all eyes maintained, or improved on, preoperative BCVA, in contrast, Jackson et al noted that $12 \%$ of eyes had lost one line of distance BSCVA at 6 months postoperatively, whereas, Dausch et al highlighted that $8 \%$ of eyes lost one or more lines of BSCVA at 1 year. Interestingly, $\mathrm{O}^{\prime}$ Brart et $a l^{50}$ noted that over a third of eyes $(37 \%)$ had lost one line of BSCVA by 2 years.

On the basis of the slow recovery and associated risks of corneal haze and refractive regression with higher attempted corrections, the panel view was that H-PRK is best reserved for only low levels of hypermetropia $(+2.00 \mathrm{D}$ or less). Therefore, none of our authors thought it an appropriate procedure for either of the two case examples.

\section{Laser in situ keratomileusis}

Utilising a LASIK technique, by applying the peripheral ablation under the corneal flap, a more stable and predictable refractive correction can be achieved than that obtained by surface based H-PRK because stromal healing and epithelial hyperplasia is inhibited. ${ }^{52}$ However the need for a large flap of at least $9 \mathrm{~mm}$ in diameter to apply a sufficiently large peripheral ablation zone can be more difficult in the small hypermetropic eye with a relatively flat cornea and current hypermetropic ablation zone diameters often equal or exceed the size of the stromal bed created by most microkeratomes. ${ }^{53}$

Zadok et $a l^{54}$ performed H-LASIK up to +5.00D on 72 eyes and found good predictability up to +3.0 dioptres of attempted correction with 89\% of eyes within plus or minus 1.0D of emmetropia but decreasing predictability at levels over +3.0D ( $52 \%$ within plus or minus $1.0 \mathrm{D}$ of emmetropia). Significant regression was noted in both low and moderate hypermetropia with $20 \%$ of eyes in the low and $33.3 \%$ in the moderate hypermetropic groups requiring retreatment. Overall, only one eye lost two lines of BSCVA. However, Davidorf et $a l^{53}$ have shown that while hypermetropic correction can be safely obtained with optical zones from 5.0 to $6.0 \mathrm{~mm}$ diameter, there is a tendency towards overcorrection with wider zones. A recent study by el Agha et a ${ }^{55}$ of 48 consecutive eyes of subjects with a mean age of more than 50 years failed to demonstrate any significant difference in refractive or visual outcome at 12 months when comparing H-PRK for corrections of a mean spherical equivalent of +2.25 with H-LASIK for corrections of a mean spherical equivalent of +1.81 . Hypermetropic LASIK is, in the opinion of three of the expert panel, the best option for low to moderate hypermetropia (to a maximum of +4.00 to +4.50 dioptres) in younger patients. However, pupil diameter needs to be carefully considered. Indeed, two of the panel recommended infrared or light enhancement measurement of the pupil size under scotopic conditions-for example, using a Colvard pupillometer. ${ }^{56}$ Frequently, younger patients have larger scotopic pupils, ${ }^{56}$ leading to the potential for pupil/ablation zone mismatch and resulting night vision symptoms. Other specific comments from the panelists included the following.

\section{Comment-T Kohnen}

A true optical zone of $6 \mathrm{~mm}$, if not more, is preferred in hypermetropic LASIK. With my current guideline of not more than $4 \mathrm{D}$ hypermetropic treatment an undercorrection in the left eye would result. This might be acceptable for a 25 year old, but over time the uncorrected visual acuity might decrease because of (a) regression and (b) after 40 years of age because of presbyopia.

\section{Comment-M Lawless}

The usual problems attributed to hypermetropic LASIK have been small optical zones, induced irregularity and excessive steepening, if too much treatment is attempted and/or the corneal power is too steep to start with. It is worth remembering that the volume of tissue removed with hypermetropic LASIK per dioptre of correction is considerably greater than it is for myopic LASIK. Attention to a residual bed thickness of approximately $250 \mu \mathrm{m}$ is still important in hypermetropic LASIK, even though most tissue removal is in the mid-periphery. Hypermetropic eyes tend on average to be smaller in an anterior/posterior length. 
The orbits tend to be deep set. Deep set eyes mean that fluid accumulates and, for optimal results, keratomes which can be modified in terms of ring size and suction are an advantage, as are methods of removing fluid with an aspirating speculum. As a general rule, hypermetropic patients who come to refractive surgery are older than myopic patients, and there may be more tear film abnormalities and a higher incidence of epithelial defects induced at the time of surgery, with subsequent secondary complications. The ages of the patients described here do not particularly put them at risk. The flap size needs to be large enough so that an appropriate ablation can be performed without taking hinge protection to an extreme.

How steep can a cornea be and still be compatible with good visual quality? It depends on the relation between the patient's pupil size, the diameter of the effective optical zone and the quality of the optical zone-that is, whether there is any degree of irregularity. I think concentrating on a specific corneal power, such as 48 or 50 dioptres as being the upper limit that should be created with hypermetropic LASIK is a little misleading. A 50 dioptre cornea with a large optical zone of good quality is compatible with good vision, whereas a 47 dioptre central power, with a small effective optical zone and some irregularity, leads to poor quality vision. There are other, perhaps more esoteric, things to consider. A normal cornea has a horizontal diameter longer than the vertical diameter. It may not be important in a myopic correction where most of the ablation is occurring, within, for example, a central $7 \mathrm{~mm}$ diameter, but it may be important for a hypermetrope. Additionally, there is a difference in corneal thickness across the horizontal meridian, with the cornea being thinner on the lateral side. The curvature tends to flatten more on the nasal side. Because of corneal thickness differences there are changes in refractive index and hydration, and these two are linked depending on what depths of cornea you measure. These differences in conjunction with scleral forces, which start to have an effect once you get close to the periphery of the cornea, must mean that there will be a bigger refractive standard deviation when we treat hypermetropes. The further you go from the geometric centre of the cornea, the more the ablation is having a different effect medially, laterally, superiorly, and inferiorly, because it is acting at a different depth within the cornea, being at a variable distance from the sclera, and acting on a cornea with different curvature to start with and different hydration. That said, LASIK with a modern flying spot laser, capable of creating a large effective optical zone of $6 \mathrm{~mm}$ or more, would be my preferred treatment option, if the desired end point was plano in the above two patients for both their eyes. This assumes a low to average corneal power to begin with, so that excessive steepening would not be a factor. Two other points are worth consideration: firstly ablation times are longer with hyperopic LASIK than with myopic LASIK and because of this good tracking during the ablation may be more important, and secondly, the excessively steep central cornea that results from LASIK theoretically may compound dry eye problems postoperatively and also lead to central epithelial lesions that are difficult to treat.
Comment-A Brahma

Having been offered non-surgical options, if the 25 year old patient still wanted to proceed, I would offer LASIK but inform her that the left eye may be slightly undercorrected because of greater regression in high hypermetropic corrections. Before offering this treatment, the eyes need to meet certain criteria including scotopic pupil size (large pupils require large optical zones with large transition zones). Hypermetropes tend to have flatter keratometry than myopes, leading to smaller flaps and thus reducing the area for ablation. Therefore, lower than normal keratometry values would exclude a patient from LASIK surgery. In order not to violate the $250 \mathrm{\mu m}$ residual bed rule to prevent late keratectasia, corneal thickness measurements need to be taken not only in the centre but outside this area (in the paracentral and mid-peripheral zones) as it is in this area that most of ablation is performed by the excimer laser. In a 45 year old with identical refraction LASIK is a feasible option, again dependent on the factors discussed for the younger patient. Once more, the left eye is at the limit of treatment parameters for hypermetropia and there is risk of undercorrection/regression. Large scotopic pupils tend not to be present in this older age group and allowance can be made for this when calculating the treatment zone.

\section{Phakic IOLs}

An alternative to corneal surgery in the correction of hypermetropia is the implantation of an intraocular lens into a phakic eye with a healthy crystalline lens. The use of such a phakic intraocular lens allows the accommodative function of the crystalline lens to be retained.$^{28} \mathrm{~A}$ further benefit is that it avoids irreversible procedures on the cornea which is intrinsically a structure designed to minimise optical aberrations and maintain lifelong refractive stability. Three broad types of intraocular lens are available-posterior chamber phakic IOLs (or intraocular "contact lenses" (ICL)) that are inserted into the posterior chamber, iris-clip anterior chamber lenses, and angle fixated anterior chamber lenses. Peer reviewed data for the use of these lenses in the correction of hypermetropia are limited at the moment.

Posterior chamber collamer foldable implants have been used for hypermetropic corrections with good results. ${ }^{28}$ The Staar posterior chamber phakic IOL was designed for the correction of moderate to high myopia and hypermetropia (range of correction from +10.0 to $-20.0 \mathrm{D}$ ). The lens is a hydrophilic collagen polymer with an optical zone between $4.5 \mathrm{~mm}$ and $5.5 \mathrm{~mm}$, which can be folded and inserted through an incision smaller than $3.0 \mathrm{~mm}$. The length of IOL used is based on the white to white measurement and then reduced by $0.5 \mathrm{~mm}$ in hypermetropic eyes to avoid undesirable vaulting (with a lens that is too large) and decentring (with a lens that is too small). Appropriate vaulting of the phakic IOL needs to be guaranteed. A minimum anterior chamber depth, from endothelium to anterior crystalline lens surface (measured ultrasonically) of $2.8 \mathrm{~mm}$ is recommended. The lens power required for each eye is calculated by Staar surgical AG. Two Nd:YAG peripheral iridotomies, 90

Debate 


\section{Debate}

degrees apart, need to be performed at least 2 weeks before surgery to prevent pupil block after implantation. Alternatively, surgical peripheral iridectomies can be performed during insertion of the lens. Theoretically, it is ideally suited to young subjects and some older subjects in the early stages of presbyopia (the advantages in older patients must be weighed against those of performing lens extraction with monofocal or multifocal IOL). Patients with scotopic pupils greater than the optical zone (4.5-5.5 mm) may develop halos or symptoms of night glare, as may patients with a decentred lens. A history of ocular pathology is a contraindication to implantation. Rosen and Gore, ${ }^{28}$ in an early study of 25 hypermetropic or myopic eyes, noted the predictability of refractive outcome to be good in hypermetropes. They also found the safety of these lenses to be reasonably good although one subject developed pupil block glaucoma in one eye and aqueous misdirection in the other, despite being pretreated with YAG peripheral iridotomies. Another potential problem is pigment dispersion.

A preliminary report of iris claw intraocular lenses for high hypermetropes by Fechner and co-authors ${ }^{57}$ discusses the potential difficulties of implantation of these lenses in short phakic eyes. One significant problem is possible ongoing corneal endothelial cell loss, and on this basis, they recommend life long monitoring of the endothelium with removal of the IOL if it is believed to be endangering the endothelium. They recommended ensuring an anterior chamber depth of more than $3.0 \mathrm{~mm}$ for middle aged patients and more than $3.5 \mathrm{~mm}$ for young patients (bearing in mind the anterior chamber tends to shallow with age). Fechner et al also highlighted the possibility of IOL luxation, low grade inflammation, and the development of glaucoma. Theoretically these lenses should not cause cataract as they do not touch the crystalline lens, although there is the potential to damage the crystalline lens at the time of surgery. Stability of the postoperative refraction was good and predictability based on postoperative refraction was adequate (mean preoperative refractive error $+9.98 \mathrm{D}+/-2.61$, mean postoperative refractive error $+0.07+/-2.03)$.

For our two case examples all of our experts would consider phakic IOLs, but with varying opinions as for which age group they were appropriate.

Opinion-Kohnen

I would only offer phakic IOL implantation for the left eye of the 25 year old (assuming sufficient anterior chamber depth and no corneal contraindications or evidence of glaucoma). However, although I would consider a phakic IOL in the 45 year old, I would be more inclined to offer clear lens extraction in view of the patient's age and loss of accommodation.

\section{Opinion-Brahma}

I would not recommend a phakic IOL in the 25 year old on the basis of possible cataractogenesis from posterior chamber phakic IOLs, possible endothelial damage from anterior chamber phakic IOLs, and the requirement for the scotopic pupil to be less than $5 \mathrm{~mm}$ to avoid visual symptoms from edge effect at night. However, I would consider phakic IOLs in the 45 year old noting that if IOL crystalline lens touch caused cataract formation then removal is possible without problems such as loss of accommodation, unlike in the younger patient.

\section{Opinion-McGhee}

The risk of cataractogenesis either because of contact of the posterior chamber phakic IOL with the crystalline lens at the time of insertion, subsequent IOL crystalline lens contact due to inadequate sizing and related forward vaulting, or nutritional compromise due to the proximity of the IOL to the anterior surface of the crystalline lens would make me very hesitant to offer this surgery to any subject under 40 years of age. However, I would consider a posterior chamber phakic IOL in the older subject but would not utilize an iris clip or angle supported IOL.

\section{Opinion-Lawless}

I would consider using a ICL in the left eye of both the 25 year old and the 45 year old in preference to clear lens extraction as preservation of accommodation is important, particularly in the 25 year old, but also the 45 year old who would retain some benefit for a few years. I would preferentially choose the Staar lens as its removal is easier than other forms of phakic IOLs should complications occur.

\section{Clear lens extraction}

Technically, a relatively easy option to treat hypermetropic patients is clear lens extraction (CLE), or refractive lensectomy, with monofocal or multifocal IOL implantation. Phacoemulsification is well established as a safe and effective procedure achieving good visual outcomes with few complications. There is a further advantage that rehabilitation and refractive stability are rapid with essentially no regression. CLE seems to be an adequate solution for refractive correction especially in high hypermetropes, ${ }^{58}$ although fine tuning of the outcome with corneal surgery might be necessary. However, there are disadvantages and potential problems with CLE. Loss of accommodation is one significant disadvantage; therefore the procedure is best reserved for presbyopic hypermetropes. Accurate selection of IOL power for shorter eyes can be a problem and is dependent on precise preoperative biometry. Axial length measurement in small eyes is critical as a small error is proportionately more significant than a similar error in a large myopic eye. Also, the best formula to use for deciding lens power in short eyes has not been clearly established..$^{59}$

The IOL power required may be higher than a single IOL can provide. Implantation of two IOLs in the bag (piggyback lenses) has been used to overcome this problem. Theoretically, because of the high levels of spherical aberration seen with thick lenses, implanting two thinner lenses should give better quality of vision although this needs to be established clinically. The choice of IOL type in this situation is important as there have been reports of interlenticular opacification (ILO) between the two lenses leading to 
hypermetropic shift as the lenses move apart. Indeed, Pop et $a l^{60}$ reported that $35 \%$ of eyes with piggyback Acrysof lenses showed ILO between 6 and 12 months postoperatively and that $64 \%$ of these had a resultant sudden hypermetropic shift of up to 2.75D. However, Fink et al, ${ }^{61}$ in a series of 50 hypermetropic eyes managed with CLE, used silicone piggyback lenses in 12 eyes ( Staar Surgical AA-4203V) and did not report any cases of ILO.

In terms of refractive outcome, Fink et $a l^{61}$ showed good predictability in eyes with hypermetropia up to $+4.0 \mathrm{D}(88.5 \%$ within $1.0 \mathrm{D}$ of intended refraction) but less accurate predictability of refractive outcome in eyes with hypermetropia over +4.0D $(58.3 \%$ within $1.0 \mathrm{D}$ of intended refraction). Overall, they had better visual results for lower levels of preoperative hypermetropia. Lyle and $\mathrm{Jin}^{62}$ performed a smaller study of 20 eyes undergoing CLE to correct hypermetropia (from +2.38D to +7.36D) and reported reasonable predictability with 75\% within 1.0D spherical equivalent of emmetropia, however, 15\% lost one line of BSCVA. Although limited by study size, they found the Holladay formula to be more accurate than the SRKII or SRK/T formulas in deciding lens power.

Following CLE any residual ametropia can potentially be corrected with lens exchange although this increases the risk of surgical complications. Another option is to perform corneal surgery to fine tune the refractive result. Pop's study ${ }^{60}$ compared the results of PRK and LASIK used to correct residual ametropia in eyes that had had CLE and PC IOL for hypermetropia (mean $+2.25 \mathrm{D})$ and found no statistical difference between the two. Overall predictability was fairly good with $79 \%$ within plus or minus 1.0D of emmetropia. Preoperative best spectacle corrected visual acuity was well correlated with that postoperatively.

Two of our panel (AB, TK) recommended CLE with PC IOL for the 45 year old case example. A superior short tunnel corneal incision of approximately 3.5-3.8 mm could be considered to reduce some of the "with the rule" astigmatism. In view of the high rate of posterior capsule opacification in this age group a foldable IOL with rectangular sharp edges was also recommended (for example, a Pharmacia 911A composed of high refractive silicone or an Alcon MA60BM composed of hydrophobic acrylic material). In addressing the problem of resultant loss of accommodation it was suggested a multifocal IOL of the "progressive zonular" type (for example, Allergan SA40) might be used in appropriate patients who might accept some loss of contrast sensitivity postoperatively. Otherwise, spectacles for near would be necessary. It was noted that if a lens power over 30 dioptres was required, with enough notice, a number of manufacturers can supply high powered PMMA IOLs to place in the bag to avoid two posterior chamber IOLs and the attendant problems with possible ILO. One of our panel (ML) would consider CLE in the 45 year old if the desired end point was $-1.0 \mathrm{D}$, requiring a refractive correction of $6.5 \mathrm{D}$, and if the anterior chamber depth was not sufficient to support an implantable contact lens. It was also commented (CMcG) that a significant benefit of this procedure is that it reduces the future risk of angle closure glaucoma in older, moderately hypermetropic eyes.
None of our four experts recommended CLE for the 25 year old case example on the basis of loss of accommodation.

\section{CONCLUSIONS}

Unlike the surgical correction of moderate to high myopia, the contemporary correction of moderate hypermetropia and astigmatism continues to raise debate and controversy. While a range of modalities, including incisional, thermal, photoablative, phakic IOLs, and phacorefractive clear lens extraction, have been employed over the past 20 years, and although LASIK may currently be the most utilised, no single technique has become the gold standard "panacea" for moderate hypermetropia, Importantly, the panel formed for this review has highlighted the need for an appropriate and extensive preoperative assessment and consideration of the subject's age and visual needs. Any assessment must include careful measurement of scotopic pupil size and its relation to the proposed ablation diameter as well as the principle that no treatment, or alternative non-surgical options, such as refitting of contact lenses, should always be considered and discussed with the patient.

With regard to surgical options, only three procedures were generally considered suitable for moderate hypermetropia $(>+3.00 \mathrm{D})$ as highlighted in the hypothetical case studies. While the authors considered the use of all three techniques, LASIK was stated as a definite option for the $+5.00 /+1.00 \mathrm{D} \times 90$ eye by only one panelist, although all panelists thought it should be considered for the less hypermetropic eye $(+3.00$ / $+1.25 \mathrm{D} \times 85$ ). Interestingly, limited enthusiasm was expressed for phakic intraocular lens surgery in the 25 year old subject, though all panel members would consider this for an identical refractive error in the 45 year old with presbyopia. Phacorefractive clear lens exchange was also reserved by all authors for the older, presbyopic, hypermetrope (Table 2).

It would appear from our panel response, that the best surgical solution for moderate hypermetropia is still an evolving situation despite increasing and more refined choices. Indeed, it is salutary to note that in the younger case scenario, all panelists were in agreement that one important option was not to recommend surgery and await further surgical developments in this dynamically changing field.

\section{REFERENCES \\ 1 Brahma A, McGhee CN. Surgical correction of refractive errors (Review). J Roy Soc Med 2000;93: $118-23$ \\ 2 McGhee CN, Anastas CN, Jenkins L, et al. The surgical and laser correction of hypermetropia. In: McGhee CNJ, Taylor HR, Trokel S, Gartry D, eds. Excimer lasers in ophthalmology: principles and practice. London: Martin Dunitz, 1997:273-94 \\ 3 Kohnen T. Advances in the surgical correction of hyperopia (editorial). J Cataract Refract Surg 1998;24:1-2 \\ 4 Duke-Elder S, Abrams D. Anomalies of the optical system. In: System of ophthalmology. Vol 5. London: Henry Kimpton, 1970:234-9. \\ 5 Wang Q, Klein BE, Klein R, et al. Refractive status in the Beaver Dam Study. Invest Ophthalmol Vis Sci 1994;35:4344-7 \\ 6 Stromberg. Refraction and axial length of human eyes. Acta Ophthalmol 1936;14:281-5. \\ 7 Anschutz T. Laser correction of hyperopia and presbyopia. Int Ophthalmol Clin 1994;42:139-43.}

Debate

(n) . 
Debate

8 Lans LJ. Experimentelle Untersuchungen uber die Entstehung von Astimatismus durch nicht-perforirende Corneawunden. Albrecht Von Graefes Arch Klin Exp Ophthalmol 1898;45:117.

9 Yamashita T, Schneider M, Fuerst D, et al. Hexagonal keratotomy reduces hyperopia after radial keratotomy in rabbits. J Refract Surg 1986;2:261-4.

10 Gilbert ML, Friedlander M, Aiello JP, et al. Hexagonal keratotomy in human cadaver eyes. J Refract Surg 1988;4:12-14.

11 Vrabec MP, Durrie DS, Hunkeler JD. Arcuate keratotomy fro the correction of spherical hyperopia in human cadaver eyes. Refract Corneal Surg 1993;9:391

12 Neumann AC, McCarty GR. Hexagonal keratotomy for correction of low hyperopia: preliminary results from a prospective study. J Cataract Refract Surg 1988;14:265-9.

13 Jensen R. Hexagonal keratotomy: clinical experience with 483 eyes. Int Ophthalmol Clin 2001;31:69-73.

14 Nordan LT, Maxwell WA. Avoid radial karatotomy with small optical zones and hexagonal keratotomy (letter) Refract Corneal Surg 1992;8:331.

15 Harr D. Sparring over hexagonal keratotomy. Refract Corneal Surg 2001:8:266-7.

16 Grandon SC, Sanders DR, Anello RD, et al. Clinical evaluation of hexagonal keratotomy for the treatment of primary hyperopia. J Cataract Refract Surg 1995;21:140-9.

17 Fyodorov S. Corneal curvature change using energy of laser radiation. (822407). 1980. Russia. (Patent)

18 Neumann AC, Fyodorov S, Sanders DR. Radial thermokeratoplasty for the correction of hyperopia. Refract Corneal Surg 1990;6:404-1 1

19 Neumann AC, Sanders DR, Raanan M, et al. Hyperopic thermokeratoplasty: clinical evaluation. J Cataract Refract Surg 1991;17:830-8.

20 Charpentier DY, Nguyen-Khoa JL, Duplessix M, et al Intrastromal thermokeratoplasty for correction of spherical hyperopia: a 1-year prospective study. J Fr Ophtalmol 1995:18:200-6.

21 Feldman ET, Ellis W, Frucht-Perry J. Regression of effect following radial thermokeratoplasty in humans. Refract Corneal Surg 1989;5:288-91.

22 Seiler T, Wollensak J. Refractive surgery of the cornea: corneal surgery - an alternative to optical aids? Fortschritte der Medizin 1991;109:579-81.

23 Siganos DS, Siganos CS, Pallikaris IG. Clear lens extraction and intraocular lens implantation in normally sighted hyperopic eyes. Refract Corneal Surg 2001;10:117-21.

24 Kezirian GM, Gremillion CM. Automated lamellar keratoplasty for the correction of hyperopia. J Cataract Refract Surg 1995;21:386-92.

25 Lyle WA, Jin GJC. Hyperopic automated lamellar keratoplasty. Arch Ophthalmol 1998:116:425-8.

26 Seiler T. Ho:YAG laser thermokeratoplasty for hyperopia. Ophthalmol Clin North Am 1993;5:773-80.

27 Koch DD, Kohnen T, McDonnell PJ, et al. Hyperopia correction by noncontact holmium:YAG laser thermal keratoplasty. United States phase lla clinical study with 1 year follow up. Ophthalmology 1996;103:1525-36.

28 Rosen E, Gore C. Staar collamer posterior chamber phakic intraocular lens to correct myopia and hyperopia. J Cataract Refract Surg 1998;24:596-606.

29 Thompson VM, Seiler T, Durrie DS, et al. Holmium:YAG laser thermokeratoplasty for hyperopia and astigmatism: an overview. Refract Corneal Surg (Suppl) 1993;9:S134-7

30 Seiler T, Matallana M, Bende T. Laser thermokeratoplasty by means of a pulsed holmium:YAG laser for hyperopic correction. Refract Corneal Surg 1990;6:328

31 Seiler T, Matallana M, Bende T. Laser coagulation of the cornea with a holmium:YAG laser for correction of hyperopia. Fortsch Ophthalmol 1991;88:121-4.

32 Parel JM, Ren Q, Simon G. Noncontact laser photothermal keratoplasty I: biophysical principles and laser beam delivery system. Refract Corneal Surg 1994; 10:511-18.

33 Simon G, Ren Q, Parel JM. Nonconatct laser photothermal keratoplasty II: refraction effects and treatment parameters in cadaver eyes. Refract Corneal Surg 1994;10:519-28.

34 Vinciguerra P, Kohnen T, Azzolini M et al. Radial and staggered treatment patterns to correct hyperopia using noncontact holmium:YAG laser thermal keratoplasty. J Cataract Refract Surg 1998;24:21-30.

35 Tutton MK, Cherry PMH. Holmium:YAG laser thermokeratoplasty to correct hyperopia: two years follow up. Ophthalmic Surgery and Lasers (Suppl) 2001;27:S521-42
36 Nano HD, Muzzin S. Noncontact holmium:YAG laser thermal keratoplasty for hyperopia. J Cataract Refract Surg 1998;24:751-7

37 Durrie DS, Schumer DJ, Cavanaugh TB. Holmium:YAG laser thermokeratoplasty for hyperopia. Refract Corneal Surg 1994; 10(Suppl):S277-80

38 Kohnen T, Husain SE, Koch DD. Corneal topographic changes after holmium:YAG laser thermal keratoplasty to correct hyperopia. J Cataract Refract Surg 1996;22:427-35.

39 Koch DD, Kohnen T, McDonnell PJ, et al. Hyperopia correction by noncontact holmium:YAG laser therma keratoplasty. United States Phase lla clinical study with 2 year follow up. Ophthalmology 1997;104:1938-47.

40 L'Esperance FA Jr, Warner JW, Telfair WB, et al. Excimer laser instrumentation and technique for human corneal surgery. Arch Ophthalmol 1989;107:131-9.

41 Dausch D, Klein R, Schroder E. Excimer laser photorefractive keratectomy for hyperopia. Refract Corneal Surg 1993;9:20-8.

42 Jackson WB, Mintsioulis G, Agapitos PJ, et al. Excimer laser photorefractive keratectomy for low hyperopia: safety and efficacy. J Cataract Refract Surg 1997:23:480-7

43 Williams DK. One-year results of laser vision correction for low to moderate hyperopia. Ophthalmology 2000; 107:72-5.

44 Dausch D, Smecka Z, Klein R, et al. Excimer laser photorefractive keratectomy for hyperopia. J Cataract Refract Surg 1997;23:169-76.

45 Carones F, Gobbi PG, Vigo L, et al. Photorefractive keratectomy for hyperopia. Ophthalmology 1999; 106:1976-83.

46 Maloney RK, Friedman M, Harman T, et al. A prototype erodibel mask delivery system for the excimer laser. Ophthalmology 1993:100:542-9.

47 Dausch D, Klein BE, Landesz $M$, et al. Photorefractive keratectomy to correct astigmatism with myopia or hyperopia. J Cataract Refract Surg 1994;20(Suppl):252-7.

48 Nagy ZZ, Krueger RR, Hamberg-Nystrom H, et al. Photorefractive keratectomy for hyperopia in 800 eyes with the Meditec MEL 60 laser. J Refract Surg $2001 ; 17: 525-33$.

49 Daya SM, Tappouni FR, Habib NE. Photorefractive keratectomy for hyperopia. Ophthalmology 1997; 104:1952-8.

50 O'Brart DPS, Stephenson CG, Baldwin H, et al Hyperopic photorefractive keratectomy with the erodible mask and Axicon system: two year follow up. J Cataract Refract Surg 2000;26:524-35.

51 McGhee CN, Ellerton CR. Complications of excimer laser photorefractive surgery. In: McGhee CN, Taylor HR, Gartry D, Trokel S, eds. Excimer lasers in ophthalmology: principles and practice. London: Martin Dunitz, 1997:379-402.

52 Arbelaez MC, Knorz MC. Lasik for hyperopia and hyperopic astigmatism. J Refract Surg 1999;15:406-14.

53 Davidorf JM, Eghbali F, Onclinx T, et al. Effect of varying the optical zone diameter on the results of hyperopic laser in situ keratomileusis. Ophthalmology 2001;108:1261-5.

54 Zadok D, Maskaleris G, Montes M, et al. Hyperopic laser in situ keratomileusis with the Nidek EC-5000 excimer laser. Ophthalmology 2000;107: 1 132-7.

55 El-Agha MS, Johnston EW, Bowman RW, et al. Excimer laser treatment of spherical hyperopia: PRK or LASIK? Trans Am Ophthalmol Soc 2000;98:59-66.

56 Schnitzler E-M, Kohnen T. Scotopic measurement of normal pupils: Colvard versus Video Vision Analyzer infrared pupillometer. J Cataract Refract Surg 2000;26:859-66.

57 Fechner PU, Singh D, Wulff K. Iris claw lenses in phakic eyes to correct hyperopia: Preliminary study. J Cataract Refract Surg 1998;24:48-56.

58 Rosen SE. Considering corneal and lenticular technique of refractive surgery (editorial). J Cataract Refract Surg 1996;23:689-91.

59 Holladay JT, Gills JP, Leidlein J, et al. Achieving emmetropia in extremely short eyes with two piggyback posterior chamber intraocular lenses. Ophthalmology 1996; 103: 1118-23

60 Pop M, Payette Y, Amyot M. Clear lens extraction with intraocular lens followed by photorefractive keratectomy or laser in situ keratomileusis. Ophthalmology 2001;108:104-11

61 Fink AM, Gore C, Rosen E. Refractive lensectomy for hyperopia. Ophthalmology 2000;107:1540-8.

62 Lyle WA, Jin GJC. Clear lens extraction to correct hyperopia. J Cataract Refract Surg 1997;23:1051-6. 